\title{
Economic evaluation of surgically trained assistant medical officers in performing major obstetric surgery in Mozambique
}

\author{
ME Kruk, a C Pereira,, F Vaz, c S Bergström, ${ }^{d}$ S Galea \\ a Department of Health Management and Policy, University of Michigan School of Public Health, Ann Arbor, MI, USA \\ ${ }^{b}$ Instituto de Ciências de Saùde, Maputo, Mozambique ${ }^{c}$ Tecnicos de Cirurgia Training Program, Instituto Superior de Ciências de Saùde, \\ Maputo, Mozambique d Division of International Health (IHCAR), Karolinska Institutet, Stockholm, Sweden ${ }^{\mathrm{e}}$ Department of Epidemiology, \\ University of Michigan School of Public Health, Ann Arbor, MI, USA \\ Correspondence: Dr ME Kruk, Department of Health Management and Policy, University of Michigan School of Public Health, \\ 109 Observatory Road, SPH II M3166, Ann Arbor, MI 48109, USA. Email mkruk@umich.edu
}

Accepted 10 March 2007.

\begin{abstract}
Objective To compare the training and deployment costs and surgical productivity of surgically trained assistant medical officers (técnicos de cirurgia) and specialist physicians (surgeons and obstetrician/gynaecologists) in Mozambique in order to inform health human resource planning in a developing country with low availability of obstetric care and severe physician shortages.

Técnicos de cirurgia have been previously shown to have quality of care outcomes comparable to physicians.
\end{abstract}

Design Economic evaluation of costs and productivity of surgically trained assistant medical officers and specialist physicians.

Setting Hospitals and health science training institutions in Mozambique.

Population Surgically trained assistants, medical officers, surgeons and obstetrician/gynaecologists in Mozambique.

Methods The costs of training and deploying the two cadres of health workers were derived from a review of budgets, annual expenditure reports, enrolment registers, and accounting statements from training institutions and interviews with directors and administrators. Productivity estimates were based on a hospital survey of physicians and técnicos de cirurgia.

Main outcome measures Cost per major obstetric surgical procedure over 30 years in 2006 US dollars.

Results The 30-year cost per major obstetric surgery was $\$ 38.9$ for técnicos de cirurgia and \$144.1 for surgeons and obstetrician/ gynaecologists. Doubling the salaries of técnicos de cirurgia resulted in a smaller but still substantial difference in cost per surgery between the groups ( $\$ 60.3$ versus $\$ 144.1$ per procedure). One-way sensitivity analysis to test the impact of varying other inputs did not substantially change the magnitude of the cost advantage of técnicos de cirurgia.

Conclusion Training more mid-level health workers in surgery can be part of the response to the health worker shortage, which today threatens the achievement of the health Millennium Development Goals in developing countries.

Keywords Developing countries, economic evaluation, human resources, obstetric surgery.

Please cite this paper as: Kruk M, Pereira C, Vaz F, Bergström S, Galea S. Economic evaluation of surgically trained assistant medical officers in performing major obstetric surgery in Mozambique. BJOG 2007;114:1253-1260.

\section{Introduction}

Maternal and neonatal mortality are two of the greatest development and moral challenges facing the world. The average woman in sub-Saharan Africa faces a 1 in 16 lifetime chance of dying in pregnancy and childbirth compared with a 1 in 30000 chance in some European countries, such as Sweden. ${ }^{1}$ The maternal mortality ratio (chance of dying in pregnancy or shortly after delivery) stands at 830/100 000 live births in Africa compared with 20 in the developed world. ${ }^{2}$ Approximately, $70 \%$ of maternal deaths in Africa are due to direct obstetric causes, such as postpartum haemorrhage, sepsis, hypertensive disease, and obstructed labour. ${ }^{3}$ As labour complications are in most cases impossible to predict in advance, timely emergency obstetric care including caesarean section should be available for all women in labour if complications arise. ${ }^{4-6}$ Health systems should also provide life-saving surgical treatment of other obstetric emergencies, including laparotomy for ectopic pregnancy and obstetric hysterectomy in cases of uncontrolled postpartum haemorrhage or ruptured uterus.

Mozambique is a low-income country in south-eastern Africa. Economic and health indicators demonstrate substantial 
material deprivation in the country. Mozambique's population is nearly 20 million, with $62 \%$ living in rural areas. Gross national income per capita is $\$ 210$, and $38 \%$ of the population has a daily income of less than $\$ 1 .^{7}$ Per capita total health expenditure was US $\$ 11$ in $2002,{ }^{7}$ and the maternal mortality ratio in 2003 was $408 / 100000 .^{8}$

Availability of maternal health services in Mozambique is limited, particularly in rural areas. While in urban areas $82.6 \%$ of women delivered in a health facility, $82.2 \%$ of women had a skilled attendant and $6.2 \%$ of women had a caesarean section, in rural areas, these figures were 35.3, 35.6 and $0.6 \%$, respectively. ${ }^{8}$ Low access in rural areas is likely a result of distance to functioning facilities ${ }^{8}$ and lack of health workers trained in obstetric care. Mozambique has 435 physicians and only 26 obstetricians for a population of nearly 20 million. ${ }^{9}$ This dearth of physicians and other providers skilled in emergency obstetric care is echoed throughout Africa. ${ }^{10}$ It is a major constraint in achieving the maternal mortality goal-one of eight Millennium Development Goals (MDGs) ${ }^{10}$ agreed to by 189 countries at the United Nations in 2000 .

Training physicians takes an average of 6-11 years and is expensive for developing countries. In addition, physicians, whose training is based on European medical school models, are extremely mobile professionals who have a high propensity to emigrate to Europe and North America and other high-income regions in search of better reimbursement, professional opportunities, and quality of life. ${ }^{11-13}$ A recent study reported that lower-income countries supply between 20 and $75 \%$ of international medical graduates practising in the USA, UK, Canada, and Australia and that 9 of the 20 countries with the highest proportion of physicians leaving to those staying behind are in sub-Saharan Africa or the Caribbean. ${ }^{14}$ For some countries, including Mozambique, an even more important problem is the geographic maldistribution of physicians within their borders. Many physicians, particularly specialists, choose to practise in the capital or in other large cities to maximise their professional and personal opportunities, leaving rural areas severely understaffed. ${ }^{15}$

Mozambique began training a new cadre of health worker known as técnicos de cirurgia in 1984, as a home-grown response to the shortage of surgeons and obstetricians, especially in rural areas, following independence and the onset of civil war. The programme has since trained 61 técnicos de cirurgia, with 55 still in active practice, mainly in rural areas. ${ }^{16}$ These mid-level health workers are trained to perform a broad range of obstetric, general, and orthopaedic surgery.

A 1996 review of 2071 caesarean sections performed by tecnicos de cirurgia and physicians ${ }^{16}$ showed that técnicos' decision making and quality of care as gauged by indications for surgery, postoperative deaths, and major complications were comparable to obstetricians. The only statistically significant difference was in the frequency of superficial wound separations, for which the odds ratio was $2.2(1.2-3.9)$ for técnicos de cirurgia. Another review ${ }^{17}$ showed that for a broad range of general and obstetric surgical procedures performed by técnicos de cirurgia, ranging from herniorrhaphy to salpingo-oophorectomy to obstetric hysterectomy, the postoperative case-fatality rates were 0.4 and $0.1 \%$ for emergency and elective cases, respectively. Pereira et al. (unpublished) have also shown that more than $90 \%$ of three graduating classes of técnicos de cirurgia stayed in rural areas for 7 years after graduation, whereas not a single physician graduating in the same years did so. The data were obtained from interviews performed in 2004, with all physicians and técnicos de cirurgia graduating in 1987, 1988, and 1996. The reported place of practice upon graduation and 2 and 7 years postgraduation was corroborated using Ministry of Health records. In light of the limited numbers of doctors practising in Mozambique today and the many decades it will take to train sufficient numbers of doctors to cover the unmet need for surgical procedures in the country, these data suggest that técnicos provide a vital service.

There is little information about the economic aspects of training and deploying técnicos de cirurgia versus physicians. This information is important in informing the policy dialogue on the feasibility of such programmes in Mozambique, as well as in other countries struggling with similar health worker shortages. This paper reports the start-up costs of a técnicos de cirurgia training programme and the costs for training and deploying técnicos and specialist physicians (obstetrician/gynaecologists and surgeons). These are the only health workers formally trained to perform major obstetric surgery in Mozambique. It also presents the 30-year cost of training and deploying técnicos de cirurgia versus obstetricians and surgeons per major obstetric surgery to demonstrate the resources required for scaling up both cadres in the longer term.

\section{Methods}

\section{Description of training programmes}

The técnicos de cirurgia training programme begun in 1983/84 by Mozambican and expatriate surgeons and obstetricians who were concerned by the shortage of surgeons in the country. The idea of a nonphysician surgeon arose from the observation that some of the nurses and medical assistants working in rural areas, in the absence of surgeons, had begun teaching themselves basic surgical techniques and practising emergency surgery. Currently, the training of técnicos de cirurgia consists of 2 years of classroom-based instruction at the Instituto Superior de Ciências de Saùde and 1 year of internship under the supervision of a surgeon in a provincial hospital. All candidates for the técnicos de cirurgia training programme must have 2 or 3 years of basic or mid-level medical training (e.g. as a nurse or a técnico de medicina, or medical assistant) and several years of rural practice. Upon passing a final 
examination, most técnicos de cirurgia are posted to district or rural hospitals, where they practise with the support and supervision of the provincial surgeon.

Medical training in Mozambique at the government university, Universidade Eduardo Mondlane, is based on a European model. The 6-year programme consists of classroom instruction in basic biomedical subjects, hospital rotations, and a final-year rural clerkship. Graduates work in rural areas for 2 years before returning for residency training. Residencies in surgery and obstetrics and gynaecology take a further 5 years. Two to three obstetricians and two to three surgeons on average graduate from the residency programme each year. While anecdotally some generalist physicians practise surgery during their rural postings (in some cases under the supervision of técnicos de cirurgia), their surgical volume is low, they are not formally trained in surgical methods, and their quality of care is unknown. Therefore, generalist physicians were not considered in this analysis.

\section{Measuring costs}

We conducted economic costing of training and deployment of técnicos de cirurgia and specialist physicians trained in surgery. This analysis provides an estimate of costs involved in replicating a similar programme in other settings, and as such full economic costs were calculated for donated inputs and volunteer time. ${ }^{18}$ We adopted a modified societal perspective, incorporating all public sector costs for the development of the training programme, training, and deployment of técnicos de cirurgia, as well as opportunity costs for health workers in training. ${ }^{18,19}$ In calculating deployment costs, we did not include all facility level costs, such as drugs, hospital bed costs or salaries of other health personnel, as based on our discussions with physicians and técnicos de cirurgia those inputs did not vary systematically between the two cadres of health workers. In addition, to provide a more complete picture of the investment requirements for the técnico training programme, we calculated the start-up costs of the técnicos de cirurgia programme; comparable data for the medical school were not available and therefore we did not include start-up costs in the comparison of costs per surgery. All costs were converted to 2006 USD using the International Monetary Fund Gross Domestic Product deflator and the average mid-year exchange rate of $\$ 1$ US $=27,030 \mathrm{MZM} .{ }^{20}$ Vehicles and office equipment were annualized using an estimated useful life of 8 years. Buildings were assumed to have a useful life of 30 years. We used a discount rate of $3 \%$ per year, as per standard guidance. ${ }^{18}$ World Health Organization's Excelbased Cost-It template was used to calculate average annual training costs, and Excel 2004 for Mac version 11.3.3 was used for all other aspects of the analysis. ${ }^{21}$

The costs of the start-up or development phase of the técnicos de cirurgia training programme were estimated retrospec- tively through discussion with the surgeons and obstetricians involved in its genesis. Although in actuality some start-up capital investments were delayed by lack of funds at the outset, all start-up costs are reported as being made at in year 0 to provide a clear idea of the upfront financial investments required for the development of a similar programme. Startup costs are presented separately and are not included in the comparison between técnicos and physicians.

The continuing costs of training of técnicos de cirurgia were based on current expenditure reports from the Instituto Superior de Ciências de Saùde and discussions with the institute director and the técnicos de cirurgia course director, as well as with the course coordinator. The component of Institute overhead costs (e.g. facility rent, cooling, and administration) attributable to the training of the técnicos de cirurgia was included in the analysis. Opportunity costs for técnico students were estimated at $80 \%$ of the salary of a técnico de medicina (medical assistant) or nurse, the students' professional qualification before entering the técnico training programme. This was based on the salary paid by the Ministry of Health to students during training. The value of any clinical services performed by técnicos in training was not included as an offset to the costs of training. The costs of first-level training for técnicos de cirurgia, i.e. basic nursing or medical assistant training, were estimated by deriving a representative per student cost from the Higher Institute of Health Sciences' global budgets for the years 2001-03, the latest available. Opportunity costs for this level of training were not included. The institute trains approximately $500-700$ basic and mid-level health workers, ranging from birth attendants to laboratory technicians to nurses.

The costs of medical training were based on the latest available budgets and annual reports of the Eduardo Mondlane University (2004) and the Faculty of Medicine (2005), as well as discussions with administrators. We excluded research expenditures unless the research had a training component. In addition to the direct costs of training, we allocated a proportion of the central university budget for administration, general support, and libraries and archives to the Faculty of Medicine proportional to its enrolment. Costs for residency training in surgery and obstetrics and gynaecology were obtained through discussions with residency programme directors. The salaries paid residents by the Ministry of Health (at the level of a GP) were used to estimate their opportunity costs. For the base-case analysis, residents were considered full-time students under supervision, and the service component of their work was not included.

Deployment costs for técnicos de cirurgia and physicians were collected from Ministry of Health salary scales and discussions with practising técnicos. Deployment costs consisted of salaries, benefits, rural incentives, continuing medical education, and the costs of physician supervision and referral for complicated cases. 


\section{Calculating productivity}

While both técnicos de cirurgia and surgeons and obstetricians perform a wide variety of surgeries, this analysis focused on the productivity of each cadre in obstetric surgery, specifically the number of caesarean sections, obstetric hysterectomies, and laparotomies for ectopic pregnancy. To calculate the annual number of each of these procedures performed by the two types of providers, surgical registers of all 34 Mozambican government hospitals with functioning surgical theatres were reviewed in 2002 (unpublished). Of these, 23 were rural/district, 8 were general and provincial, and 3 were central hospitals. The accuracy of the data was confirmed through a review of labour room records that indicated that $99 \%$ of all maternity patients referred for surgery were included in the surgical registers. Surgical procedures, like costs, were discounted at 3\% per year. Access to essential obstetric surgery is in itself a valued output of the health system and has the advantage of being easily understood by policy makers and the public, thus, we chose to use tecnicos' and physicians' productivity in performing these surgeries as an intermediate output in this study. Using disability adjusted life years (DALYs) or other health outcome measures here would also be misleading, as the available data on surgical productivity only capture a small part of the técnicos' de cirurgia and physicians' impact on life savings, given their much broader scope of surgical practice. By contrast, DALYs are used to measure the effects of an intervention on all future averted morbidity and mortality. ${ }^{18,19}$

The annualized and discounted costs of training and deploying técnicos de cirurgia and physicians were calculated over a 30-year period, corresponding to a potential length of a career. For each cadre of health worker, the net present value of the 30-year cost stream was then divided by the discounted number of major obstetric surgeries performed, beginning with the year following the completion of all training, to obtain the cost per major obstetric surgery.

Sensitivity analysis was performed to model the impact on the results of varying analytic assumptions. Given the concern, universally voiced by informants during the course of this study, that técnicos de cirurgia are substantially underpaid (current salary is approximately $\$ 200$ per month), and the well-documented importance of appropriate remuneration for retention of health professionals ${ }^{22,23}$ sensitivity analyses were performed to model the impact of doubling the salaries of the técnicos. We adjusted productivity levels for both cadres to account for possible changes in productivity since 2002 and of reducing the opportunity costs for physicians in residency training to account for the service component of their work.

\section{Results}

\section{Costs}

Development of the técnicos de cirurgia training programme was estimated at an investment cost of $\$ 144,723$ (Table 1).
Table 1. Start-up costs of técnicos de cirurgia training

\begin{tabular}{lrr}
\hline Cost category & \multicolumn{1}{c}{ Cost } & $\%$ \\
\hline Professional salaries & $\$ 32,940.3$ & 22.8 \\
Materials and supplies & $\$ 7110.0$ & 4.9 \\
Computers & $\$ 9000.0$ & 6.2 \\
Travel & $\$ 277.5$ & 0.2 \\
Books & $\$ 30,000.0$ & 20.7 \\
Rural surgery text & $\$ 33,442.7$ & 23.1 \\
Library building & $\$ 31,952.6$ & 22.1 \\
Total start-up costs & $\$ 144,723.0$ & 100.0 \\
\hline
\end{tabular}

Just less than one-quarter of the cost was for professional salaries. Approximately two-thirds was for books and equipment, including a library, computers, anatomic models, and the development of a textbook for técnicos.

The breakdown of post-start-up costs for the core training of técnicos de cirurgia and physicians (técnicos de cirurgia course and medical school) is shown in Table 2. The técnicos de cirurgia programme costs $\$ 4881$ per student per year or $\$ 14,644$ over the 3 years of the training. Medical school training costs were $\$ 3573$ per year or $\$ 21,437$ over 6 years. Salaries for teachers and building costs were higher for medical students, whereas student support expenses (pocket money and support for rural clerkship) were higher for técnico students.

Table 2. Undiscounted average annual and total costs of técnicos de cirurgia training and medical school

\begin{tabular}{|c|c|c|c|c|}
\hline Category & Tecnicos & $\%$ & Physicians & $\%$ \\
\hline \multicolumn{5}{|l|}{ Personnel } \\
\hline $\begin{array}{l}\text { Administrative/management } \\
\text { salaries }\end{array}$ & $\$ 677.0$ & 13.9 & $\$ 709.4$ & 19.9 \\
\hline Teaching/supervision salaries & $\$ 761.6$ & 15.6 & $\$ 1598.8$ & 44.7 \\
\hline Travel allowances & $\$ 50.6$ & 1.0 & $\$ 7.3$ & 0.2 \\
\hline \multicolumn{5}{|l|}{ Goods and services } \\
\hline Office supplies & $\$ 267.2$ & 5.5 & $\$ 64.1$ & 1.8 \\
\hline $\begin{array}{l}\text { Books and equipment } \\
\text { (computers and models) }\end{array}$ & $\$ 268.3$ & 5.5 & $\$ 218.8$ & 6.1 \\
\hline $\begin{array}{l}\text { Building rent, } \\
\text { utilities, maintenance, } \\
\text { and other overhead }\end{array}$ & $\$ 160.0$ & 3.3 & $\$ 397.0$ & 11.1 \\
\hline $\begin{array}{l}\text { Transport } \\
\text { (capital and recurrent) }\end{array}$ & $\$ 282.1$ & 5.8 & $\$ 23.3$ & 0.7 \\
\hline \multicolumn{5}{|l|}{ Student support } \\
\hline Accommodation and food & $\$ 0.9$ & 0.0 & $\$ 299.8$ & 8.4 \\
\hline Pocket money & $\$ 1673.2$ & 34.3 & $\$ 193.2$ & 5.4 \\
\hline Rural clerkship & $\$ 740.5$ & 15.2 & $\$ 61.1$ & 1.7 \\
\hline Total per year & $\$ 4881.4$ & 100.0 & $\$ 3572.8$ & 100.0 \\
\hline Total for full course & $\$ 14,644.3$ & & $\$ 21,437.0$ & \\
\hline
\end{tabular}


Residency training costs were $\$ 10,539$ per year or $\$ 52,693$ over 5 years. Because of the nature of the residency training programme, which resembles an apprenticeship with few overhead and didactic teaching expenditures, the majority of the costs were for resident and instructor salaries, with books, equipment, and travel costs comprising less than $20 \%$ of total costs.

The total cost (excluding start-up) of producing one técnico de cirurgia, including first-level training (as a nurse or a técnico de medicina) was $\$ 19,465$ per student. The comparable cost for producing one specialist physician (surgeon or obstetrician/gynaecologist) was $\$ 74,130$ (Table 3 ). The annual cost of deploying técnicos de cirurgia and specialist physicians were $\$ 3859.0$ and $\$ 10,367.7$, respectively. The majority of the deployment cost were salaries; the costs of additional supervision and referral for técnicos were \$196.4 per person per year or $5.1 \%$ of total.

Figure 1 compares 30-year training and deployment costs for técnicos de cirurgia and physicians. While training costs are higher for physicians, due to the longer period of training and higher in-training salaries, the bulk of the difference between the career costs of técnicos de cirurgia and physicians lies in the substantially higher salaries paid to specialist physicians after completion of training.

\section{Productivity}

In 2002, 47 specialist physicians and 53 técnicos de cirurgia performed a total of 5264 and 6914 major obstetric surgeries (caesarean sections, obstetric hysterectomies, and laparotomies for ectopic pregnancy), respectively (unpublished). On average, each técnico performed 117 caesarean sections, 7 obstetric hysterectomies, and 7 laparotomies for ectopic pregnancy, annually. Comparable numbers for specialists were 102, 4, and 6. These figures were used to represent annual productivity for major obstetric surgery throughout the career of the two cadres.

Table 3. Comparison of undiscounted average annual and total training costs for técnicos de cirurgia and specialist physicians

\begin{tabular}{lrrr}
\hline & Cost per year & Years & Course cost \\
\hline $\begin{array}{l}\text { Tecnicos de cirurgia } \\
\text { First-level training }\end{array}$ & $\$ 1606.8$ & 3 & $\$ 4820.4$ \\
$\begin{array}{l}\text { Tecnico de cirurgia course } \\
\text { Total cost }\end{array}$ & $\$ 4881.4$ & 3 & $\$ 14,644.3$ \\
of training & & & $\$ 19,464.7$ \\
$\begin{array}{l}\text { Physicians } \\
\text { Medical school }\end{array}$ & $\$ 3572.8$ & 6 & $\$ 21,437.0$ \\
Residency training & $\$ 10,538.6$ & 5 & $\$ 52,692.8$ \\
$\begin{array}{l}\text { Total cost } \\
\text { of training }\end{array}$ & & & $\$ 74,129.8$ \\
\hline
\end{tabular}

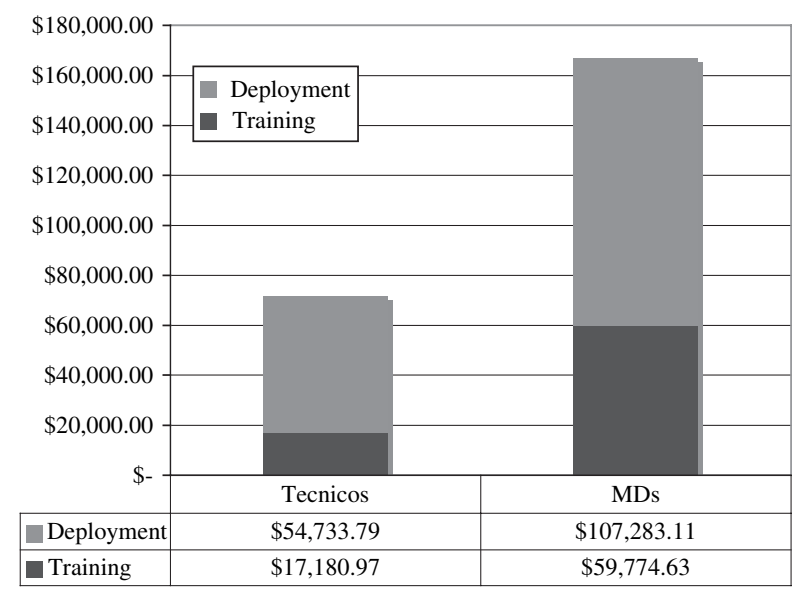

Figure 1. Comparison of 30-year training and deployment costs for técnicos de cirurgia and physicians.

\section{Cost per surgery and sensitivity analysis}

The 30-year discounted costs of training and deployment, not including start-up, are \$71,914.8 and \$167,057.7 for técnicos de cirurgia and physicians, respectively. Técnicos de cirurgia perform 1850 surgeries, while physicians perform 1159 surgeries (discounted) in the same timeframe largely because of their longer period of training. The resulting cost per surgery for técnicos de cirurgia is $\$ 38.87$ versus $\$ 144$.1 for physicians, as shown in Figure 2. Today técnicos de cirurgia earn less than operating room scrub nurses in Mozambique (Mozambique Ministry of Health, unpublished). If their salaries were to double, their cost per major surgery would still be less than

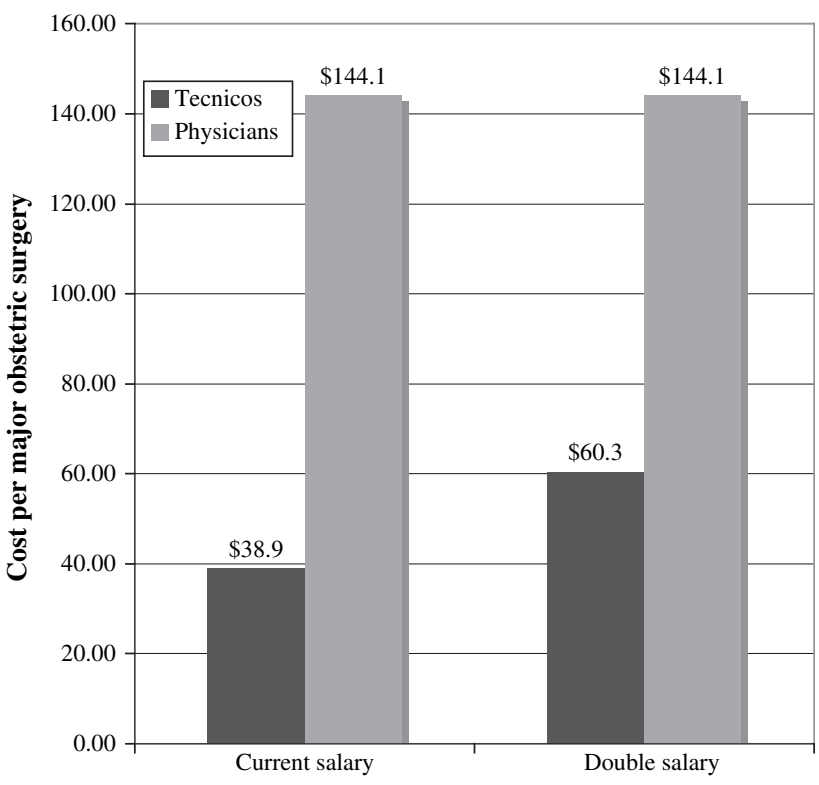

Figure 2. Discounted 30-year cost per surgery ratios for técnicos de cirurgia and physicians at current salaries and at double salary for técnicos. 
half that of physicians (Figure 2). The results of one-way sensitivity analysis of varying other key assumptions is shown in Table 4. Técnicos de cirurgia retain a substantial cost advantage in all of the scenarios.

\section{Discussion}

We showed here that a técnicos de cirurgia programme in Mozambique is a good investment with the costs per major obstetric procedure for técnicos averaging 27\% of physician costs over their careers. This, in concert with evidence that the técnicos' indications for surgery and complication rates are comparable with those of physicians ${ }^{16,17}$ make a strong argument for investing in técnicos de cirurgia as part of the solution to the health worker crisis in Mozambique. In addition, técnicos are more likely to remain in rural areas after deployment than are physicians (unpublished) suggesting that this cadre of health workers can provide surgical services at a reasonable cost, where they are most needed in Mozambique.

There are a number of caveats to consider in interpreting the results. The costs of deploying both técnicos and physicians are highly sensitive to salary levels. This is a crucial issue in addressing the current health worker shortages in Africa and elsewhere in the developing world. We showed here that even with a doubling of their salaries, investing in técnicos de cirurgia is good value. Cost data for residency training and first-level medical training for tecnicos were based on discussions with programme directors and global budgets, respectively, which did not permit a detailed cost breakdown. We show that varying those cost estimates by $50 \%$ to account for uncertainty around these estimates does not change the basic conclusion of the study.

All economic evaluation is sensitive to the choice of effectiveness measures. Our analysis focuses on major obstetric surgical procedures. The cost per surgery would fall dramatically if one were to include the full range of surgeries (e.g. abdominal, trauma, orthopaedic, and paediatric etc.) that these professionals perform. We show that if productivity were to increase by $50 \%$ (e.g. adding other key procedures), the cost per surgery would fall substantially for both cadres. Further work that quantified the full scope of surgical procedures and their impact on DALYs saved would be valuable.

The lack of cost data on building a medical school prevents us from comparing the development costs of a técnicos de cirurgia and physician training. This is an important limitation as it prevents estimation of what a scale-up of each programme would cost. For example, in Mozambique, the director of the técnicos de cirurgia training programme estimates that by expanding training to the provinces, the output of the training programme could be increased to 30 per year from 30 every 3 years, without large additional capital costs. This is not likely the case for the medical school, which is operating close to maximum capacity. The costs for this analysis were gathered retrospectively from official budgets and reports; in the case of start-up costs, verbal recall was used to augment written records. While a prospective design may have allowed for more contemporaneous data collection, hence possibly minimising recall bias, this was not possible due to resource limitations. Therefore, given the time elapsed since programme initiation in 1984, the start-up costs involve a greater degree of uncertainty than the continuing programme costs.

Lastly, the costs reported here may not be extrapolated to other countries, given the specific nature of national training programmes for mid-level providers. For example, surgically trained assistant medical officers in other countries are trained using an apprenticeship model, which could be expected to be less expensive to administer. However, the difference in the cost per surgery of mid-level providers and physicians may be less favourable to the former in other countries where GPs are trained to do obstetric surgery. However, governments would still have to tackle the difficulty of retaining physicians in rural areas. Economic evaluations of other training models would give a more complete picture of the cost-effectiveness of surgically trained mid-level providers.

Table 4. Results of the base-case and one-way sensitivity analysis on the cost per major obstetric surgery of tecnicos de cirurgia and specialist physicians

\begin{tabular}{|c|c|c|c|}
\hline Variation tested & $\begin{array}{l}\text { Cost per surgery } \\
\text { tecnicos }\end{array}$ & $\begin{array}{c}\text { Cost per surgery } \\
\text { physicians }\end{array}$ & $\begin{array}{c}\text { Difference in cost } \\
\text { per surgery }\end{array}$ \\
\hline Base case ( $3 \%$ discount rate) & $\$ 38.9$ & $\$ 144.1$ & $\$ 105.3$ \\
\hline Using $5 \%$ discount rate & $\$ 41.4$ & $\$ 158.5$ & $\$ 117.1$ \\
\hline Doubling of tecnicos salaries & $\$ 60.3$ & $\$ 144.1$ & $\$ 83.9$ \\
\hline Increasing productivity by $50 \%$ for both cadres & $\$ 25.9$ & $\$ 96.1$ & $\$ 70.2$ \\
\hline Reducing opportunity cost for residency training by $50 \%$ & $\$ 38.9$ & $\$ 132.3$ & $\$ 93.4$ \\
\hline Increasing costs of first level tecnicos training by $50 \%$ & $\$ 40.1$ & $\$ 144.1$ & $\$ 104.0$ \\
\hline
\end{tabular}




\section{Conclusion}

The results of this study should not be taken to imply that policy makers would or should choose one health worker cadre over another based on cost alone. Mid-level providers such as técnicos de cirurgia are complementary to, not substitutes for, physicians. Given the magnitude of the health worker crisis, both physicians and mid-level providers will be required in substantially larger numbers in Mozambique and in other developing countries. Countries will make decisions about the appropriate mix of providers depending on local need and specific circumstances. Analysing the costs and effectiveness (productivity, safety, and quality of care) of different mixes of health workers from various cadres could aid those decisions. Evidence from Mozambique suggests that training more mid-level health workers in surgery is a good investment in responding to the health worker shortage, which is threatening the achievement of the health MDGs in developing countries.

\section{Acknowledgements}

This study was financially supported by the University of Michigan Global Health Research and Training programme and the Averting Maternal Death and Disability programme (AMDD) at the Mailman School of Public Health, Columbia University. AMDD is funded by the Bill and Melinda Gates Foundation. An earlier draft of the paper was presented at the African Union Meeting of Health Ministers in Maputo, Mozambique on September 18, 2006. The authors would like to thank the Ministry of Health, the Institute of Health Sciences, and Eduardo Mondlane University for their support in this project. In particular, Dr Rui Alves Pereira, Deputy Director for Planning, and Dr Emilia Martins, Deputy Director for Administration, in the medical school provided invaluable assistance with the costs of medical training, and Mr Maurice Malate in the administration department of Universidade Eduardo Mondlane shared his financial expertise with the authors. Mr Raimundo Malalane, the coordinator of the técnicos de cirurgia programme was exceedingly helpful in collecting cost data. Dr Colin McCord, one of the founding fathers of the técnicos de cirurgia programme in Mozambique, explained the origins and motivation of the programme, provided start-up cost data and gave helpful feedback on drafts. Dr Lilia Jamisse from the Ministry of Health made very helpful comments on a draft of the paper. Profs Sharon Maccini and Daniel Eisenberg provided assistance with the interpretation of results. Finally, we express our gratitude to the técnicos de cirurgia and physicians working throughout Mozambique with great skill and dedication.

\section{References}

1 Ronsmans C, Graham WJ; The Lancet Maternal Survival Series steering group. Maternal mortality: who, when, where, and why. Lancet 2006; 368:1189-22.

2 WHO. Maternal Mortality in 2000: Estimates Developed by WHO, UNICEF and UNFPA. Geneva, Switzerland: WHO, 2003.

3 Khan KS, Wojdyla D, Say L, Gulmezoglu AM, Van Look PF. WHO analysis of causes of maternal death: a systematic review. Lancet 2006;367:1066-74.

4 Rosenfield A, Maine D. Maternal mortality - a neglected tragedy: where's the M in MCH? Lancet 1985;2:83-5.

5 Dubey RD. Maternal mortality reduction by improving emergency obstetric care (EmOC) service. J Indian Med Assoc 2005;103:414.

6 WHO. World Health Report 2005 - Make Every Mother and Child Count. Geneva, Switzerland: WHO, 2005.

7 WHO. Global Health Atlas. Measure DHS, Statcompiler. WHO, 2005. [www.who.int/globalatlas]. Accessed 14 February 2006.

8 ORC Macro. Mozambique DHS 2003. 2003.

9 Jamisse L, Songane F, Libombo A, Bique C, Faundes A. Reducing maternal mortality in Mozambique: challenges, failures, successes and lessons learned. Int J Gynecol Obstet 2004;85:203-12.

10 United Nations. Road map towards implementation of the Millennium Declaration (A/56/326). New York, NY: United Nations; 2001 Sep.

11 Hagopian A, Thompson MJ, Fordyce M, Johnson KE, Hart LG. The migration of physicians from sub-Saharan Africa to the United States of America: measures of the African brain drain. Hum Resour Health 2004;2:17.

12 Hagopian A, Ofosu A, Fatusi A, Biritwum R, Essel A, Gary Hart L, et al. The flight of physicians from West Africa: views of African physicians and implications for policy. Soc Sci Med 2005;61:1750-60.

13 Astor A, Akhtar T, Matallana MA, Muthuswamy V, Olowu FA, Tallo V, et al. Physician migration: views from professionals in Colombia, Nigeria, India, Pakistan and the Philippines. Soc Sci Med 2005;61: 2492-500.

14 Mullan F. The metrics of the physician brain drain. N Engl J Med 2005; 353:1810-18.

15 Dussault G, Franceschini MC. Not enough there, too many here: understanding geographical imbalances in the distribution of the health workforce. Hum Resour Health 2006;4:12.

16 Pereira C, Bugalho A, Bergstrom S, Vaz F, Cotiro M. A comparative study of caesarean deliveries by assistant medical officers and obstetricians in Mozambique. Br J Obstet Gynaecol 1996;103:508-12.

17 Vaz F, Bergstrom S, Vaz M da L, Langa J, Bugalho A. Training medical assistants for surgery. Bull World Health Organ 1999;77:688-91.

18 Drummond MF, Sculpher MJ, Torrance GW, O'Brien BJ, Stoddard GL. Methods for the Economic Evaluation of Health Care Programmes, 3rd edn. Oxford: Oxford University Press, 2005.

19 Gold MR, Siegel JE, Russell LB, Weinstein MC. Cost-effectiveness in Health and Medicine. New York, NY: Oxford University Press, 1996.

20 IMF. World Economic Outlook Database. 2006. [www.imf.org/external/ pubs/ft/weo]. Accessed 14 July 2006.

21 Adam T, Aikins M, Evans D. Costlt Software 2005. Geneva: Switzerland. World Health Organization. [www.who.int/choice]. Accessed 12 June 2006.

22 Narasimhan V, Brown H, Pablos-Mendez A, Adams O, Dussault G, Elzinga $G$, et al. Responding to the global human resources crisis. Lancet 2004;363:1469-72.

23 Dussault G, Dubois C-A. Human resources for health policies: a critical component in health policies. Hum Resour Health 2003;1:1-16. 


\section{Commentary on 'Economic evaluation of surgically trained assistant medical officers in performing major obstetric surgery in Mozambique'}

Several important aspects should be taken into consideration when conducting an economic evaluation. One such aspect is the issue of including all relevant comparators in the economic analysis. ${ }^{1}$ This matter is often not given as much attention as it is warranted and, if overlooked too hastily, researchers might be allowing potential biases to enter into their study from the onset of its conception/design. In the case of the study conducted by Kruk et al., ${ }^{2}$ a potential comparator which has been ruled out of the analysis was the possibility of comparing surgically trained assistant medical officers (técnicos de cirurgia) to a 'no intervention' or 'do nothing' comparator. The need for such personnel as técnicos de cirurgia is evident from the situation presented by the authors for Mozambique. Indeed, their very necessity comes from the fact that formally trained surgeons in all specialities (not just obstetrics and gynaecology) are few, and their availability is limited at best. As a result, an appropriate comparator to técnicos de cirurgia would be a 'do nothing' comparator as opposed to using formally trained surgeons. Indeed, by using surgeons as the comparator, the authors are introducing a bias against técnicos de cirurgia, as a more realistic alternative for patients treated by técnicos de cirurgia would be no formal treatment at all which would, it is presumed, result in far worse outcomes for the patients.

Another aspect that deserves particular attention when conducting an economic evaluation is the choice of outcome measure. ${ }^{1}$ The authors assumed that the quality of work performed by both types of workers is comparable. ${ }^{2}$ For this reason, the number of obstetric and gynaecological surgeries performed by surgeons and técnicos de cirurgia was the chosen outcome measure. This is a very strong assumption to make and may undervalue the quality of work conducted by the surgeons, and accordingly, may inflate the effectiveness of técnicos de cirurgia. Owing to the constraints of information and data available, the use of the chosen outcome measure, although not without its shortcomings, may well be appropriate. A stronger economic evaluation would have included, at the very least, the quality of all surgeries/tasks performed by both cadres of health workers (not exclusive to obstetric and gynaecological surgeries) and the quantity of surgeries performed to allow longer term outcomes such as disability adjusted life years to be calculated. Consideration of the inclusion of 'no intervention' as a comparator would have also allowed this study to convey a fuller grasp of the wider issues surrounding this health problem to both the reader and healthcare decision makers alike.

The reader should bear in mind that the economic evaluation presented by Kruk et al. ${ }^{2}$ does suffer from some limitations. As a consequence they need to critically consider the importance of these limitations to their own situation. Despite this, the study is useful, not just for decision-makers in Mozambique and in other low-income countries, but also more generally, as the issue of substituting potentially less costly and less skilled healthcare providers for scarce, highly skilled practitioners is a growing one worldwide.

Robyn M. de Verteuil

\section{Acknowledgements}

The author would like to acknowledge Dr Luke Vale for commenting on an earlier draft of this piece of work. This work was carried out by Robyn de Verteuil of the Health Economics Research Unit and Health Services Research Unit, University of Aberdeen. The views expressed in this paper are those of the author alone. Any errors are the responsibility of the author.

\section{Disclosure of interests}

The Health Services Research Unit and the Health Economics Research Unit are both core funded by the Chief Scientist Office of the Scottish Executive Health Department.

\section{References}

1 Drummond MF, Jefferson TO. Guidelines for authors and peer reviewers of economic submissions to the BMJ. BMJ 1996;313:275-83.

2 Kruk ME, Pereira C, Vaz F, Bergstrom S, Galea S. Economic evaluation of surgically trained assistant medical officers in performing major obstetric surgery in Mozambique. BJOG 2007;114:1253-1259. 